\title{
Process scale up and characterization of wood cellulose nanocrystals hydrolysed using bioethanol pilot plant
}

\author{
Aji P. Mathew*, Kristiina Oksman, Zoheb Karim, Peng Liu, \\ Saad Ahmed Khan, Narges Naseri \\ Composite Centre Sweden, Division of Materials Science, Luleå University of Technology, 97187 Luleå, Sweden
}

\section{A R T I C L E I N F O}

\section{Article history:}

Received 27 November 2013

Received in revised form 8 March 2014

Accepted 17 April 2014

Available online 9 May 2014

\section{Keywords:}

Cellulose nanocrystals

Scale up

mechanical properties

$\mathrm{X}$-ray photoelectron spectroscopy

wood

\begin{abstract}
A B S T R A C T
The paper discusses the isolation of cellulose nanocrystals $\left(\mathrm{CNC}_{\mathrm{BE}}\right)$ from wood resources by integrating the processing with pilot-scale bioethanol processing unit. The nanocrystals were isolated from cellulose obtained by acid pretreatment of wood chips in a bioethanol pilot-scale facility, followed by a series of chemical processes and subsequent homogenization using a lab-scale homogenizer. The isolated nanocrystals had diameters of $5-15 \mathrm{~nm}$, cellulose I crystalline structure and formed a thick semi-transparent gel at low concentration ( $2 \mathrm{wt} \%$ ). XPS data showed that these nanocrystals had predominantly $\mathrm{O}=\mathrm{C}-\mathrm{O}$ surface groups which also contributed to its high negative zeta potential. $\mathrm{Casted} C N \mathrm{C}_{\mathrm{BE}}$ films showed excellent mechanical performance (200 MPa of strength, $16 \mathrm{GPa}$ of modulus) and transparency and were also found to be cytocompatible. The developed process route resulted in high-quality nanocellulose crystals with a yield of $600 \mathrm{~g} / \mathrm{day}$.
\end{abstract}

(C) 2014 Elsevier B.V. All rights reserved.

\section{Introduction}

Nanocellulose was isolated from natural resources following a top-down approach, taking advantage of its natural hierarchical structure. Isolation and use of biobased nanomaterials has been an area of great interest in materials science research during the last few decades.

Since the first reports on cellulose nanocrystal isolation from wood pulp by Rånby in the 1950s, several natural resources like wheat straw, crab shell, tunicates, plant fibres, etc., have been used by researchers to prepare nanocrystals via chemical processes (Rånby, 1952; Dufresne, 2008; Marchessault, 1959; Samir, 2005; Eichhorn et al., 2010; Mathew et al., 2009; Siro and Plackett, 2010). The chemical process involves the removal of the amorphous region from cellulose using either sulphuric acid or hydrochloric acid and subsequent neutralization and individualizing of nanocrystals using ultrasonication. The earlier reports also point to the fact that the ease of isolation, yield of the isolation process as well as the dimensions of the isolated nanocrystals depend on the raw material source. Wood can provide good yield compared to lower plants and agricultural sources, as wood has about $40 \%$ cellulose content (Hon, 1996; Han and Rowell, 1996). Furthermore, refined cellulose raw material from industry which can be directly isolated

\footnotetext{
* Corresponding author. Tel.:+46 920493336

E-mail address: aji.mathew@ltu.se (A.P. Mathew).
}

to cellulose nanocrystals without any specific purification step can provide higher yield. In this context, raw material sources of interest were wood pulp, MCC, etc, which are commercial grades of cellulose with high purity. Many studies report the use of these commercial cellulose sources as starting material for processing of cellulose nanocrystals and nanofibres with high yield efficiency (Edgar and Gray, 2003; Bondeson et al., 2006). Our earlier study on MCC (Bondeson et al., 2006) resulted in processing of CNC at a rate of $50 \mathrm{~g} /$ week (with $30 \%$ yield w.r.t. initial weight) and provided an improved yield compared to processing of CNC from bioresources like tunicates, wheat straw, etc.

In the recent years, there have been increased efforts to scale up the processing and enhance the efficiency and economy of nanocellulose isolation. CNC isolation in large scale has been reported in recent years because economical and efficient processing of $\mathrm{CNC}$ is essential for utilizing $\mathrm{CNC}$ as reinforcement or functional additive in commercial products. Most of these attempts to scale up processing have been made in Canada and the USA. For example, FP Innovations Canada reported a production rate of $3 \mathrm{~kg} /$ day, CelluForce Canada $1000 \mathrm{~kg} /$ day and FPL, US Forest Services $50 \mathrm{~kg} /$ week, following a sulphuric acid hydrolysis process (FutureMarkets, 2012; Chauve and Bras, 2014).

Bioresidues and industrial side-streams are of interest in this context and Oksman and co-workers have reported the use of different by-products or residues from forest industries as potential sources for nanocellulose production economically or even at negative cost (Oksman et al., 2011; Jonoobi et al., 2012; Herrera et al., 
2012a,b). Cellulose nanocrystals were also isolated from bioethanol residue by mechanical treatments like homogenization or sonication and showed similar properties as nanocrystals isolated from other sources by acid hydrolysis (Oksman et al., 2011; Herrera et al., $2012 \mathrm{~b})$. These raw materials were considered as potential sources for isolation of CNCs in large scale.

The current study aims to prepare nanocellulose in bench scale by integrating the lab-scale process with pilot-scale processes existing in wood-based industries. The cellulose obtained from acid hydrolysis using a pilot-scale bioethanol unit was isolated into nanocellulose by mechanical processes in the laboratory. The isolation efficiency, scaling-up potential and quality of final product were evaluated. The properties of the isolated materials and their potential applications in reinforced composites or functional materials are evaluated using mechanical testing, surface characteristics, transparency and cytocompatibility studies. It is expected that scaled-up production of nanocellulose from residues economically and efficiently, with good mechanical and functional properties will facilitate the commercial scale processing of biobased nanostructured products.

\section{Experimental}

\subsection{Materials}

Unbarked wood chips of Norway spruce (Picea abies) with a dry matter content of $50-55 \%$ were used as the raw material for the processing of cellulose nanocrystals ( $\mathrm{CNC}$ ) following the bioethanol processing route at the pilot-scale facility at SEKAB, Örnsköldsvik, Sweden.

The other chemicals used, $\mathrm{NaOH}, \mathrm{NaClO}_{2}$, toluene, sulphuric acid (96\%), etc., are of reagent grade and were purchased from VWR, Sweden.

\subsection{Methods}

\subsubsection{Isolation of cellulose nanocrystals}

The isolation process is summarised in Fig. 1. Unbarked wood chips of Norway spruce (Picea abies) with a dry matter content of $50-55 \%$ were treated in a continuous mode with sulphur dioxide in a 301 reactor at a temperature of $200^{\circ} \mathrm{C}$, at a pressure of 20 bars, and with a residence time of $7 \mathrm{~min} .3 \%(\mathrm{w} / \mathrm{w})$ of $\mathrm{SO}_{2}$ was used as catalyst. The $\mathrm{pH}$ after pre-treatment was about 2 and the total solids content was $28-30 \%$. The slurry was then diluted with water to facilitate pumping and the water insoluble solids content of the diluted slurry was about $17 \%$. The solid material of the slurry was then separated from the liquid using a membrane filter press. The solid material was stored in plastic bags at $4{ }^{\circ} \mathrm{C}$ for subsequent use.

The product obtained had cellulose and high amount of lignin and some extractives, which was refined to pure cellulose following TAPPI test method T204 for extraction of cellulose (TAPPI T204).

The first step to purify the solid matter obtained from the bioethanol plant, was the Soxhlet extraction for $6 \mathrm{~h}$ at $150^{\circ} \mathrm{C}$ using tolune/acetone mixture (2:1 ratio), where by extractives were removed. This material was then bleached using a mixture of $700 \mathrm{ml}$ deionised water, $1.5 \mathrm{ml}$ acetic acid, $6.7 \mathrm{~g}$ sodium chlorite, at $70^{\circ} \mathrm{C}$ for $12 \mathrm{~h}$. Four further additions of acetic acid and sodium chlorite were made every $2 \mathrm{~h}$ and kept for another $12 \mathrm{~h}$, where by a pure white material was obtained. After $24 \mathrm{~h}$ of bleaching the materials were washed with excess of deionized water and concentrated to $17 \mathrm{wt} \%$ solid content by centrifugation. The FTIR data of the product obtained after this process showed typical cellulose structure a with peaks at $3350 \mathrm{~cm}^{-1}, 2929 \mathrm{~cm}^{-1}, 1312 \mathrm{~cm}^{-1}$ and $1057 \mathrm{~cm}^{-1}$ of $\mathrm{C}-\mathrm{H}$ stretching, $\mathrm{C}-\mathrm{H}$ bending and $\mathrm{C}-\mathrm{O}$ stretching bonds of cellulose (spectrum not shown), being also verified in our earlier report where cellulose was isolated from bioethanol residue following this process route (Oksman et al., 2011).

The purified cellulose was made into $2 \mathrm{wt} \%$ suspensions, mixed well with shear mixture and passed through the APV 2000 highpressure homogenizer (Denmark) at a pressure of 500 bars. The suspension with a batch size of 21 was passed through the homogenizer 10 times to obtain a thick gel of nanocrystalline cellulose, and the processing time was $40 \mathrm{~min}$ per batch. This product obtained is denoted as $\mathrm{CNC}_{\mathrm{BE}}$.

CNC was also prepared from wood pulp by sulphuric acid hydrolysis in lab-scale, following the procedure reported by Bondeson et al. (2006) and was used as reference. The sulphuric acid hydrolyzed nanocrystals prepared in lab-scale is denoted as $\mathrm{CNC}_{\mathrm{H}_{2} \mathrm{SO}_{4}}$.

\subsubsection{Nanofilms and nanopaper preparation}

Thin films and nanopaper mats of $\mathrm{CNC}_{\mathrm{BE}}$ were prepared using (a) casting and (b) filtration and pressing processes, respectively.

Casted films were prepared by drying $40 \mathrm{ml}$ of $1 \%$ suspensions of CNC under ambient conditions for approximately $48 \mathrm{~h}$ in petri dishes. The resultant films had thicknesses in the range of 100-200 microns.

Nanopaper mats were prepared by vacuum filtration of $120 \mathrm{ml}$ of $0.5 \%$ suspension using Whatman filter paper (Pore size number 3 and $125 \mathrm{~mm}$ diameter) at -1.0 bar. The CNC filter cakes were dried in ambient temperature under $30 \mathrm{~N}$ load for 3 days to keep the nanopaper wrinkle free. The resultant nanopaper mats had thicknesses in the range of 600-700 microns.

$\mathrm{CNC}_{\mathrm{H}_{2} \mathrm{SO}_{4}}$ films were prepared only via the casting method, due to experimental difficulties with the filtration and pressing process with this material.

\subsection{Characterization}

Optical microscopy images of the nanoparticle suspensions were collected using a Leica Optical Microscope using suspension of $0.1 \mathrm{wt} \%$. An atomic force microscope, Nanoscope V, Veeco Instruments (Santa Barbara, CA, USA), was used to examine the morphologies of the $\mathrm{CNC}_{\mathrm{BE}}$. A drop of diluted suspensions of each sample was deposited onto freshly cleaved mica and left to dry at room temperature. All the samples were imaged in tapping mode. Height, amplitude and phase images were recorded. The instrument was operated at a resonance frequency of $350 \mathrm{kHz}$ and a spring constant of $10-200 \mathrm{~nm}^{-1}$. The diameter measurements were conducted by Nanoscope V software.

Viscosity of the CNC gels were measured using a Vibro Viscometer (SV 10/SV 100, A\&D Company, Ltd, Japan) at $22^{\circ} \mathrm{C}$. Measurements were recorded until the viscosity values were stable and the values were reported after $30 \mathrm{~min}$.

The thermal stability of the nanomaterials was studied by thermogravimetric analysis Q500 (TGA), TA Instruments (New Jersey, USA), at a temperature range of $30-500^{\circ} \mathrm{C}$ in an air atmosphere. The temperature was increased at a rate of $10^{\circ} \mathrm{C} / \mathrm{min}$ and the sample weight was $5-10 \mathrm{mg}$. All thermal stability curves show the calculated average values and each sample was tested in triplicate.

The zeta potentials of the materials at different $\mathrm{pH}$ were measured using a Zetasizer nano ZS, Malvern, at $25^{\circ} \mathrm{C}$. The concentrations of all measured samples remained the same at $0.05 \mathrm{wt} \%$.

X-ray photoelectron spectroscopy (XPS) was used to understand the surface groups on the produced nanocrystals. All XPS spectra were collected with Axis Ultra DLD electron spectrometer (Kratos

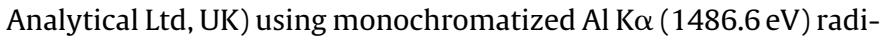
ation. Survey spectra were collected from 1100 to $0 \mathrm{eV}$ at pass energy of $160 \mathrm{eV}$. High resolution C 1s, O 1s, F 1s and Si 2p spectra were collected at pass energy of $20 \mathrm{eV}$ with a scan step of $0.1 \mathrm{eV}$. In order to minimize possible $\mathrm{X}$-ray induced degradation 


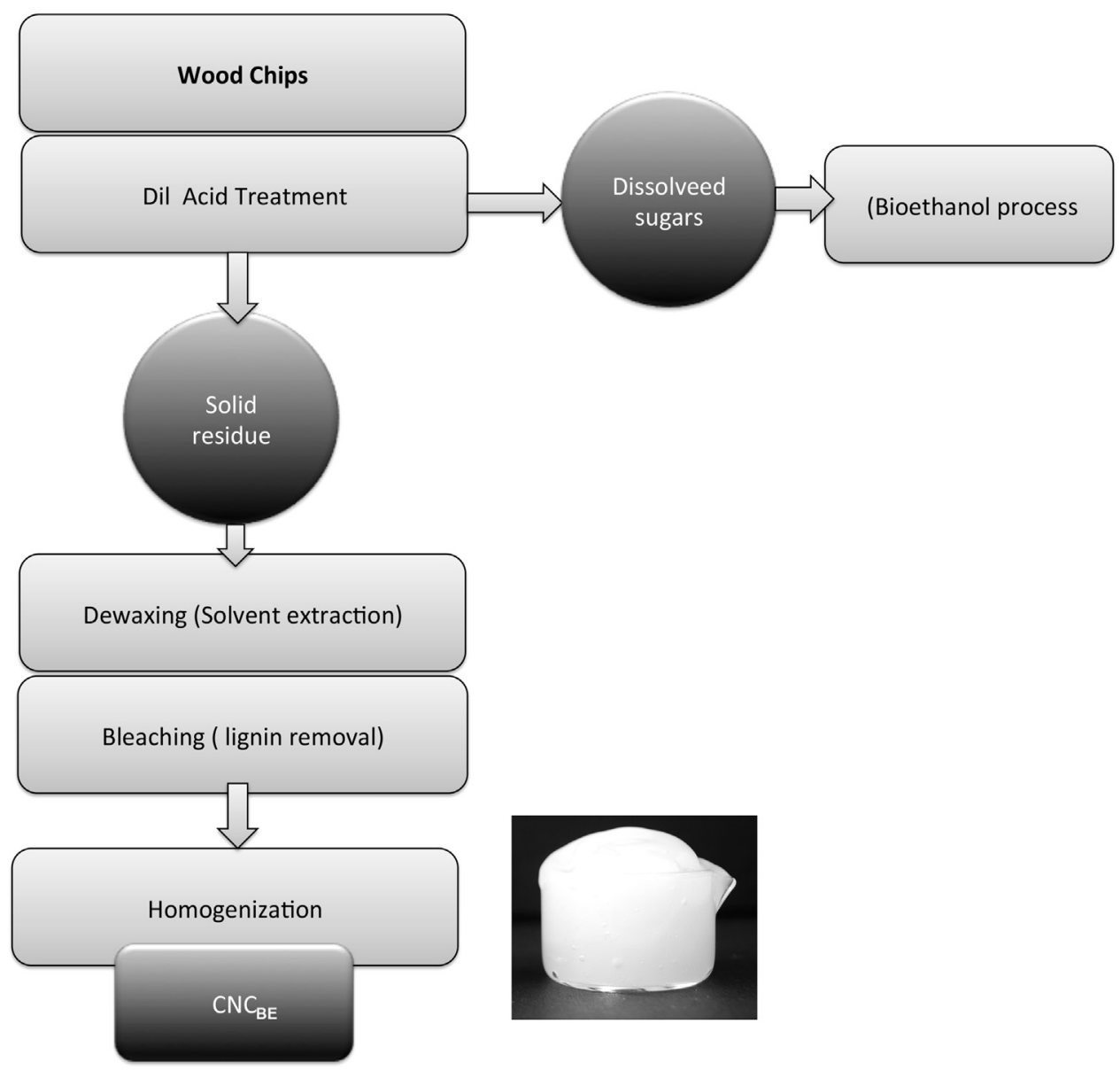

Fig. 1. Schematic representation of the processing of $\mathrm{CNC}_{\mathrm{BE}}$ and the gel obtained after the process.

of the samples, $\mathrm{C} 1 \mathrm{~s}$ and $\mathrm{O}$ 1s spectra were measured within first 10 min of exposure. Processing of the spectra was accomplished by Kratos software. High-resolution XPS spectra were fitted using linear combinations of 70:30 Gauss-Lorentzian functions on Shirley background-subtracted spectra. Binding energy (BE) scale was calibrated using aliphatic C 1 s component, set at $285.0 \mathrm{eV}$.

Casted films of CNC were analyzed at the same temperature by step scanning on the Siemens diffractometer D5000 (Berlin, Germany) to understand the crystallinity of the nanomaterials. The angle of incident monochromatic X-ray was in the range of $2 \Theta=10^{\circ}-30^{\circ}$ with a step size of 0.0263 . The wavelength of the monochromatic X-ray was $1.540598 \AA(K \alpha 1)^{\circ}$. The percentage crystallinity is calculated using Segals equation (Segal et al., 1959).

$\mathrm{CI}(\%)=\frac{I\left(22^{\circ}\right)-I\left(18^{\circ}\right)}{I\left(22^{\circ}\right)} \times 100 \%$

$\mathrm{CI}(\%)$ in the equation (1) stands for crystalline index of cellulose. $I_{\left(22^{\circ}\right)}$ (arbitrary units) represents the peak diffraction intensity corresponding to crystalline cellulose and $I_{\left(18^{\circ}\right)}$ is the peak diffraction intensity corresponding to the amorphous sections in cellulose, at $22^{\circ}$ and $18^{\circ}$ respectively.

Tensile tests were performed using strips with dimensions of $5 \mathrm{~mm} \times 50 \mathrm{~mm}$ on a universal testing machine, Shimadzu Autograph AG-X (Japan); with a load cell of $1 \mathrm{kN}$. The gauge length was $20 \mathrm{~mm}$, at a strain rate of $2 \mathrm{~mm} / \mathrm{min}$. The elastic modulus was calculated from the initial part of the slope from stress-strain curves. At least five tests were performed for each sample and the average values are presented.

Transparency tests were performed using a UV-visible spectrophotometer (Perkin Elmer, Lambda 2S). CNC films of approximately $50 \times 10 \mathrm{~mm}$ were cut and fitted in the sample holder and transmittance was measured over the wavelength region from near ultraviolet (300-400) to visible light (400-800 nm). An empty sample holder was used as a reference. The films were also photographed digitally, against a printed surface to visually observe and compare transparency.

Biocompatibility of CNC and CNF casted films was studied by direct contact test systems. The material was fixed to cell culture dish and the cells (adipose derived stem cells and cell line L929) were seeded evenly throughout the cell culture dish. The impact of the biomaterial on cell growth and morphology was monitored and documented with photographs up to 15 days.

\section{Results and discussion}

\subsection{Isolation process}

Fig. 1 shows the scheme of the integration of the $\mathrm{CNC}_{\mathrm{BE}}$ isolation process with the bioethanol pilot-scale production unit. In the case of bioethanol process after the acid hydrolysis step the liquid fraction of dissolved hemicellulose and amorphous cellulose is collected, where as in the case of $\mathrm{CNC}_{\mathrm{BE}}$ process, the solid residue stream is collected for further processing. The solid residue obtained was purified to cellulose by bleaching and solvent extraction and thereafter isolated to nanocrystals by a simple mechanical process of homogenization. It may be noted that further acid hydrolysis is not required to obtain $\mathrm{CNC}_{\mathrm{BE}}$ because it was done at the first step of bioethanol processing. Here the main advantage over starting from pulps or other purified cellulose sources as microcrystalline cellulose is that when acid hydrolysis occurs in 

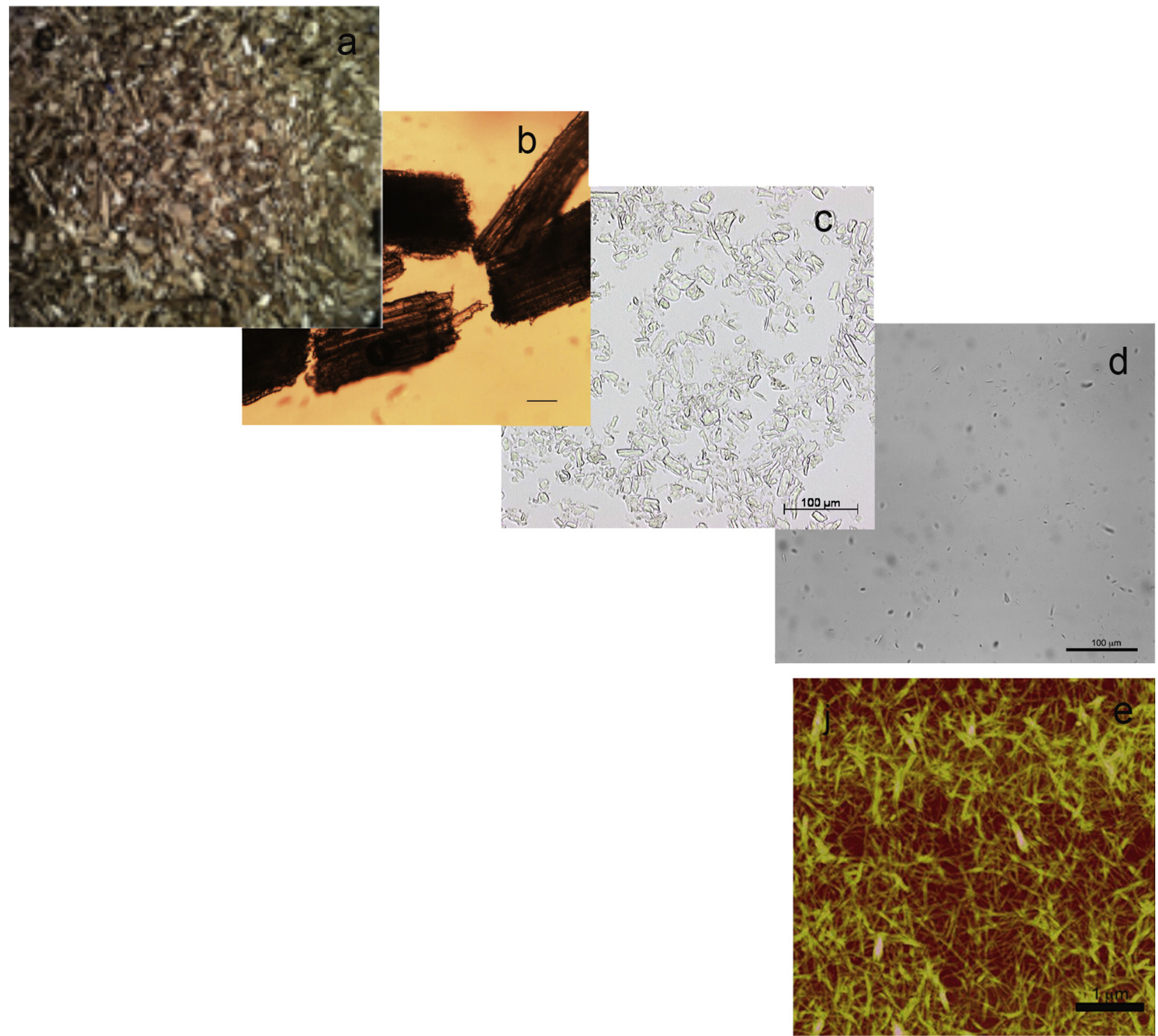

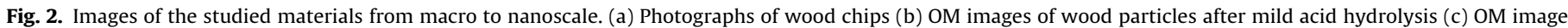
after chemical refining (d) OM image after homogenization to nanocrystals and (e) the AFM image of isolated nanocrystals.

the bioethanol pilot-scale unit, the material handled in each step is significantly higher and difficulties related to handling of acids and neutralization in the lab is avoided.

The acid hydrolysis of wood using a bioethanol pilot-scale unit provided materials in large quantities for further processing to cellulose. The yield of the acid hydrolysis step was $46 \%$. After the solvent extraction step to remove extractives, $85 \%$ yield was observed and $71-77 \%$ yield was recorded after the bleaching step, which removed lignin. This corresponds to $30 \%$ pure cellulose with respect to the wood chips at the start. $\mathrm{CNC}_{\mathrm{BE}}$ isolation by homogenization process resulted in a $100 \%$ conversion rate with respect to purified cellulose.

Optical microscopy (OM) and atomic force microscopy (AFM) were used as a tool to study the extent of isolation of the raw material to nanoscaled cellulose and are given in Fig. 2. Figures on the left (Fig. 2a) show the starting materials used. Fig. 2b shows the OM image of the wood particles after the acid hydrolysis step in the pilot-scale facility and OM images of purified wood cellulose (after solvent extraction and bleaching) used for isolating the nanoparticles are shown in Fig. 2c. Fig. 2d shows the OM of the suspension obtained after the homogenization, where microscaled particles are not visible, indicating that the isolation process has been effective in preparing nanoscaled materials. Atomic force microscopy (AFM) in Fig. 2e gives the nanoscaled information of the isolated materials. The isolated $\mathrm{CNC}_{\mathrm{BE}}$ had diameters in the range of 5-15 $\mathrm{nm}$. Accurate length determination was not possible from AFM images. The material mostly showed nanocrystal morphology, though some longer nanofibril like structures were also present to a limited extent.

The viscosity of the suspensions increased significantly during mechanical isolation of $\mathrm{CNC}_{\mathrm{BE}}$ and formed thick gels at low concentrations (see Fig. 1). The viscosity of the $\mathrm{CNC}_{\mathrm{BE}}$ suspensions at $2 \mathrm{wt} \%$ increased from $5 \mathrm{mPa}$ s before grinding to $1440 \mathrm{mPa} s$ after 10 passes through the homogenizer. Gel formation at low concentration is an indication of large surface area, which in turn suggests isolation into nanoscaled structures. $\mathrm{CNC}_{\mathrm{BE}}$ gels at $2 \mathrm{wt} \%$ concentrations showed a semi-transparent nature (see Fig. 1). 

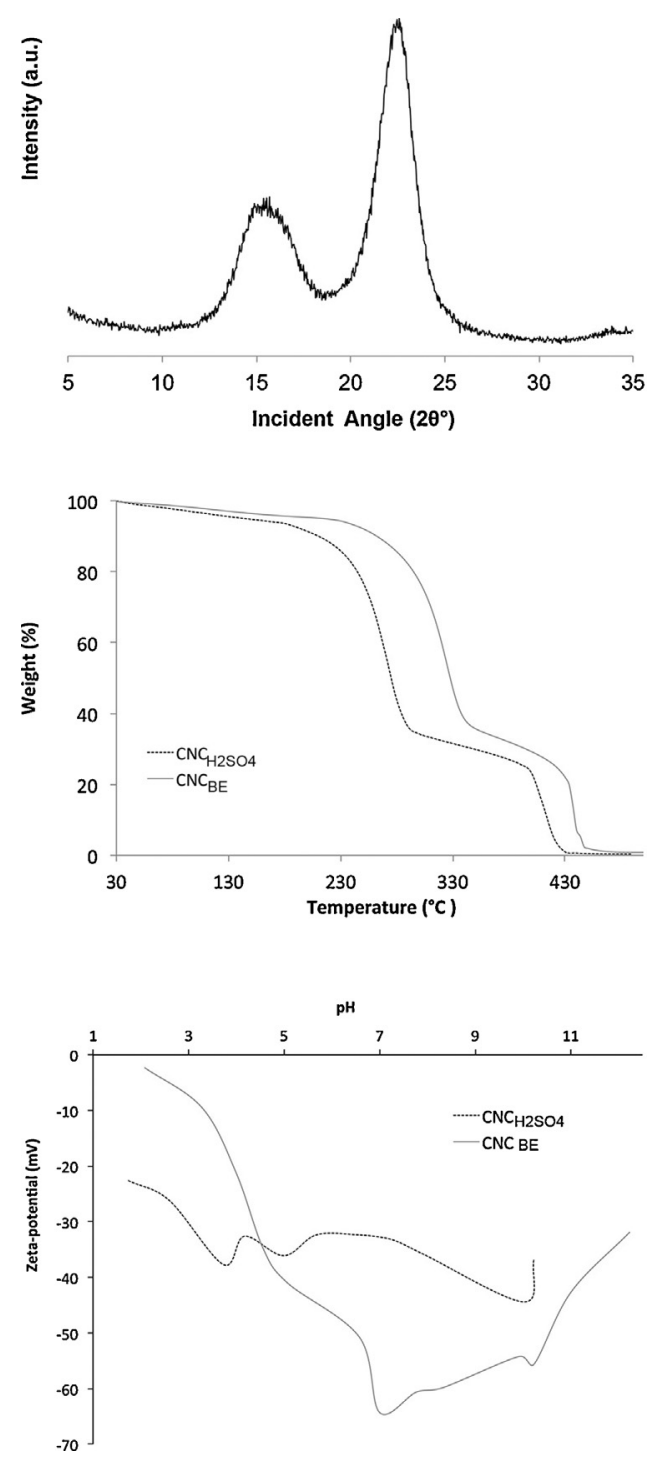

Fig. 3. $\mathrm{XRD}, \mathrm{TGA}$ and zeta potential data of $\mathrm{CNC}_{\mathrm{BE}}$.

\subsection{Physical properties}

The $\mathrm{CNC}_{\mathrm{BE}}$ films showed high crystallinity and well defined peaks were visible in the X-ray diffractograms (See Fig. 3a). CNC diffractogram showed peaks at $2 \theta=14.1^{\circ}, 16.2^{\circ}$ and $22.3^{\circ}$, indicating typical cellulose I structure (Krässing, 1996; Klemm et al., 2005). The percentage crystallinity calculated using Segals's equation from the XRD curves was found to be $77 \%$ for CNC. Higher crystallinity of $\mathrm{CNC}$ indicates that the process of nanocrystal isolation was efficient to remove amorphous regions. This value is comparable to CNC crystallinity values obtained by acid hydrolysis of MCC (Herrera et al., 2012a; Bondeson et al., 2006).

$\mathrm{CNC}_{\mathrm{BE}}$ is found to be thermally stable until $240^{\circ} \mathrm{C}$ (see Fig. 3b) and has higher stability than sulphuric acid hydrolyzed CNC. CNC isolated in the current study by homogenization does not have sulphate groups on the surface that induce the degradation of cellulose and therefore has better thermal stability that traditional acid hydrolyzed nanocrystals. (Roman and Winter, 2004; Bondeson et al., 2006; Herrera et al., 2012a,b).

Zeta potential of the prepared nanomaterial suspensions as a function of $\mathrm{pH}$ is shown in Fig. 3c. The zeta potentials of $\mathrm{CNC}_{\mathrm{BE}}$ remained negative in the studied $\mathrm{pH}$ range, which was attributed to negative surface charge, possibly from carboxyl groups. The zeta
Table 1

A comparative study of $\mathrm{C} 1 \mathrm{~s}$ and $\mathrm{O} 1 \mathrm{~s}$ spectrum of $\mathrm{CNC}_{\mathrm{SL}}$ and $\mathrm{CNC}_{\mathrm{BE}}$.

\begin{tabular}{|c|c|c|c|c|c|}
\hline & \multicolumn{2}{|l|}{$\mathrm{CNC}_{\mathrm{BE}}$} & \multicolumn{2}{|l|}{$\mathrm{H}_{2} \mathrm{SO}_{4}$} & \\
\hline & BE, eV & AC, at.\% & BE, eV & AC, at.\% & \\
\hline \multirow[t]{4}{*}{$\mathrm{C} 1 \mathrm{~s}$} & 285.0 & 10.62 & 285.0 & 24.17 & $\mathrm{C}-(\mathrm{C}, \mathrm{H})$ \\
\hline & 286.6 & 40.86 & 286.6 & 37.2 & $\mathrm{C}-\mathrm{OH}$ \\
\hline & 288.0 & 9.57 & 288.1 & 4.47 & $\mathrm{O}-\mathrm{C}-\mathrm{O}$ \\
\hline & 289.2 & 2.21 & 289.5 & 3.45 & $\mathrm{COOH}$ \\
\hline $01 \mathrm{~s}$ & 533.0 & 35.28 & 532.0 & 23.87 & \\
\hline
\end{tabular}

potential was more negative for $\mathrm{CNC}_{\mathrm{BE}}$ compared to $\mathrm{CNC}$ prepared by sulphuric acid hydrolysis in our laboratory (see the dotted lines in Fig. 3c for comparison).

Survey XPS spectra of treated $\mathrm{CNC}_{\mathrm{BE}}$ and $\mathrm{CNC}_{\mathrm{H}_{2} \mathrm{SO}_{4}}$ show different core-level photoelectron peaks attributed to $\mathrm{C}$ and $\mathrm{O}$ atoms are the main components. Theoretically, pure nanocellulose exhibits two peaks (around 533 and $285 \mathrm{eV}$ ) in the full XPS spectra, which correspond to oxygen and carbon, respectively (Siqueira et al., 2010). Both these peaks are present in XPS spectra for $\mathrm{CNC}_{\mathrm{BE}}$ and $\mathrm{CNC}_{\mathrm{H}_{2} \mathrm{SO}_{4}}$ shown in Fig. 4. Table 1 illustrates the introduction of more oxygen at $533 \mathrm{eV}$ in $\mathrm{CNC}_{\mathrm{BE}}$ compared to $\mathrm{CNC}_{\mathrm{H}_{2} \mathrm{SO}_{4}}$ indicating the more oxygen containing moeties on $\mathrm{CNC}_{\mathrm{BE}}$ surface. Further examination of full XPS spectra of $\mathrm{CNC}_{\mathrm{H}_{2} \mathrm{SO}_{4}}$ (Fig. 4b) confirmed the presence of traces of sulfur in the spectrum, $\mathrm{S} 2 \mathrm{p}$ at approximately $165 \mathrm{eV}$ and S 2s at approximately $230 \mathrm{eV}$ (detectable only in detailed analysis and not visible here) and its absence in $\mathrm{CNC}_{\mathrm{BE}}$. This indicates the presence of $-\mathrm{SO}_{3}-$ groups on $\mathrm{CNC}_{\mathrm{H}_{2} \mathrm{SO}_{4}}$ as expected. A small amount of $\mathrm{Na}$ and $\mathrm{F}$ were also detected, which might be impurities.

The main C1s signals for both nanocrystals are decomposed and are shown in the inset. Theoretically, the deconvolution of C1s signal for pure cellulose should exhibit two peaks associated to $\mathrm{C}-\mathrm{O}$ of alcohols and ethers groups and $\mathrm{O}-\mathrm{C}-\mathrm{O}$ for acetal moieties while in practice the XPS analysis of cellulose always reveals four C peaks: $\mathrm{C}-\mathrm{C} / \mathrm{C}-\mathrm{H}(\mathrm{C} 1,285 \mathrm{eV}), \mathrm{C}-\mathrm{OH}(\mathrm{C} 2,286.6 \mathrm{eV}), \mathrm{O}-\mathrm{C}-\mathrm{O}(\mathrm{C} 3$, $288.0 \mathrm{eV}$ ) and $\mathrm{COOH}(\mathrm{C} 4,289.2 \mathrm{eV}$ ) (Siqueira et al., 2010) (see Fig. 4 and Table 1). Both $\mathrm{CNC}_{\mathrm{BE}}$ and $\mathrm{CNC}_{\mathrm{H}_{2} \mathrm{SO}_{4}}$ in Fig. 4 (inset) showed all peaks corresponding to carbon atoms $\mathrm{C} 1, \mathrm{C} 2, \mathrm{C} 3$ and $\mathrm{C} 4$. The magnitude of $\mathrm{C} 2$ and $\mathrm{C} 3$ peaks is however higher in $\mathrm{CNC}_{\mathrm{BE}}$, which indicate the presence of more $\mathrm{C}-\mathrm{OH}$ and $\mathrm{O}=\mathrm{C}-\mathrm{O}$ on the surface of $\mathrm{CNC}_{\mathrm{BE}}$ compared to $\mathrm{CNC}_{\mathrm{H}_{2} \mathrm{SO}_{4}}$. The XPS study shows that $\mathrm{CNC}_{\mathrm{BE}}$ has more surface groups with as carboxyl and carbonyl groups probably introduced during weak acid hydrolysis and the subsequent bleaching steps.

The $\mathrm{O}=\mathrm{C}-\mathrm{O}$ groups on $\mathrm{CNC}_{\mathrm{BE}}$ can be considered responsible for its negative zeta potential where as $\mathrm{SO}_{3}-$ and $\mathrm{O}=\mathrm{C}-\mathrm{O}$ on $\mathrm{CNC}_{\mathrm{H}_{2} \mathrm{SO}_{4}}$ contribute to its negative zeta potential. However, the $\mathrm{O}=\mathrm{C}-\mathrm{O}$ groups on $\mathrm{CNC}_{\mathrm{BE}}$ is significantly higher (almost double) compared to $\mathrm{CNC}_{\mathrm{H}_{2} \mathrm{SO}_{4}}$, which explains the high negative zeta potential of $\mathrm{CNC}_{\mathrm{BE}}$. Our recent studies also showed that negatively charged nanocellulose are capable of preferentially adsorbing positively charges entities as heavy metal ions or dyes from water (Liu et al., 2014; Karim et al., 2014) and therefore $\mathrm{CNC}_{\mathrm{BE}}$ with high negative zeta potential have potential as functional nanomaterial in water cleaning.

Table 2

Mechanical properties of films and mats of the prepared materials.

\begin{tabular}{lclc}
\hline Material & Stress (MPa) & Strain (\%) & Young Modulus (GPa) \\
\hline $\mathrm{CNC}_{\mathrm{BE}}$ (Casting) & $204.64^{ \pm 20.06}$ & $2.23^{ \pm 0.57}$ & $16.11^{ \pm 1.33}$ \\
$\mathrm{CNC}_{\mathrm{BE}}$ (Filt and press) & $97.58^{ \pm 8.29}$ & $2.47^{ \pm 0.59}$ & $7.25^{ \pm 1.18}$ \\
\hline
\end{tabular}



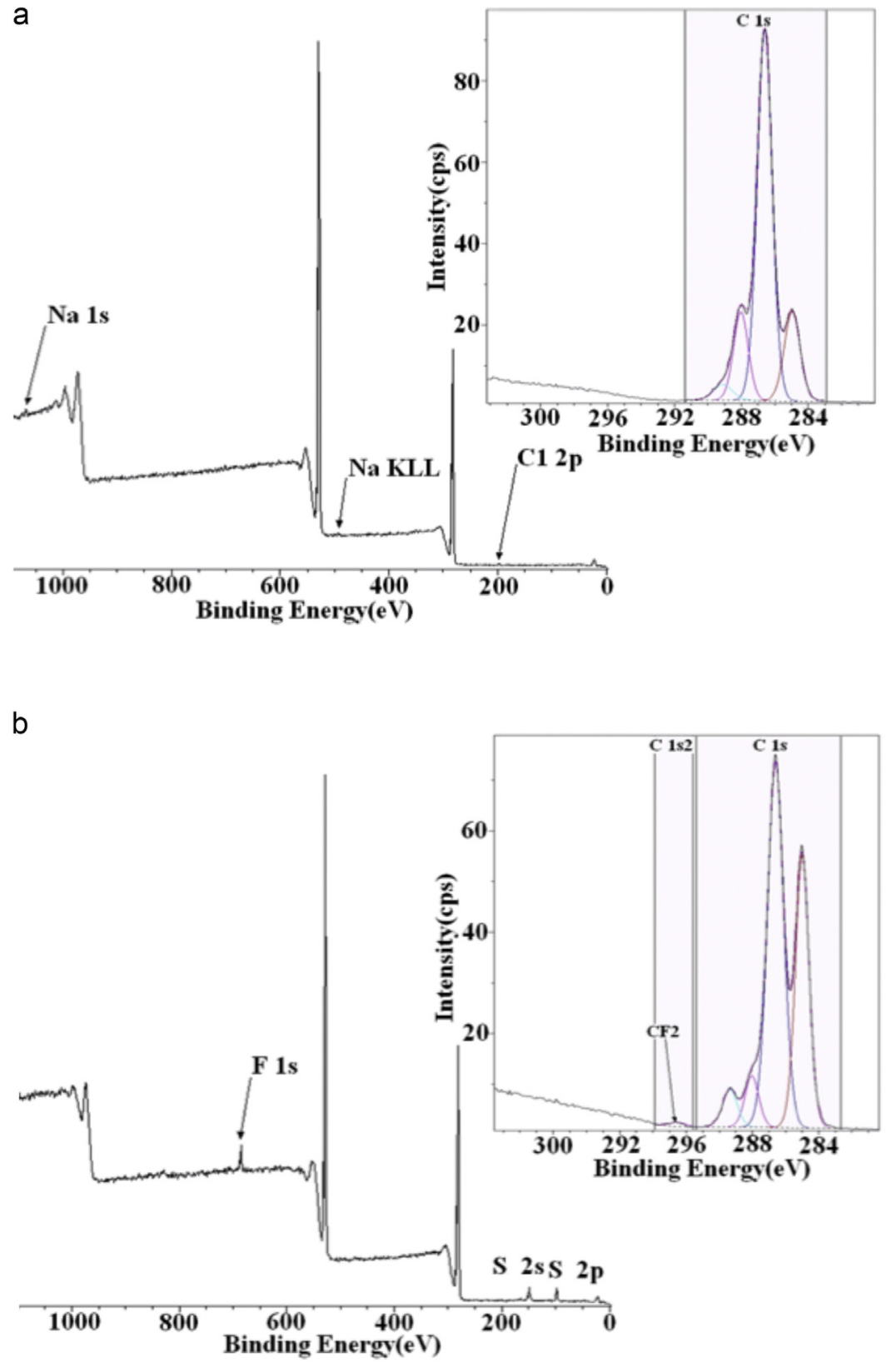

Fig. 4. XPS survey spectra of a) $\mathrm{CNC}_{\mathrm{BE}}$ and $\mathrm{CNCH}_{2} \mathrm{SO}_{4}$ and the representative $\mathrm{C} 1 \mathrm{~s}$ photoemission spectra (inset).

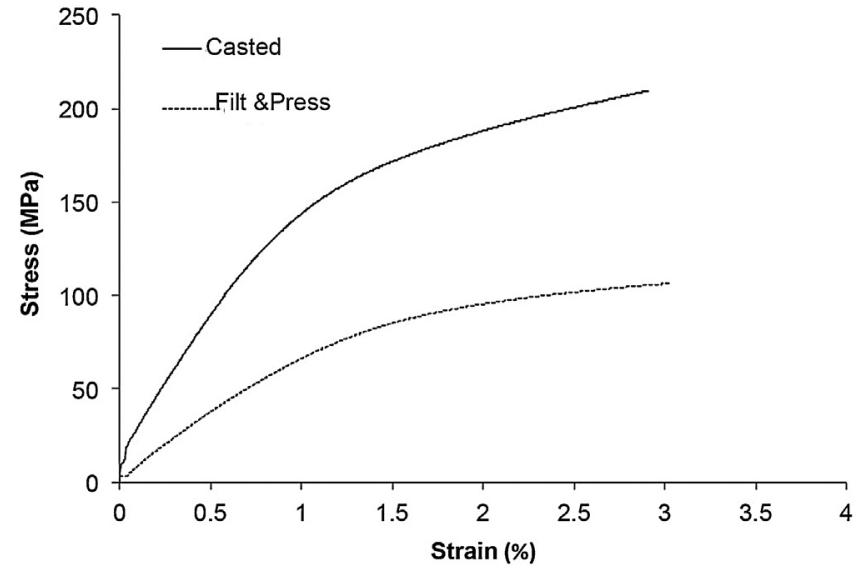

Fig. 5. Stress-strain curves of the films and nanopapers of $\mathrm{CNC}_{\mathrm{BE}}$.

\subsection{Mechanical properties}

Tensile properties of the mats and films prepared from the nanomaterials were evaluated to understand the effect of the processing methods on the mechanical properties. The mechanical properties are also considered as an indirect measure of the degree of isolation to nanoscale. The data obtained are given in Table 2 and the stress-strain curves are shown in Fig. 5.

$\mathrm{CNC}_{\mathrm{BE}}$ showed the best mechanical performance of all the studied materials. The casted films had strength as high as $204 \mathrm{MPa}$ and modulus of $16.11 \mathrm{GPa}$. The strain at break was similar for $\mathrm{CNC}_{\mathrm{BE}}$ materials prepared by casting as well as filtration and pressing. The big drop in tensile strength and modulus for the $\mathrm{CNC}_{\mathrm{BE}}$ prepared by filtration and pressing compared to casted films was unexpected. One possible explanation for the higher mechanical strength for casted films of CNC may be due to less voids, which resulted from slow and organized compacting of nanoparticles during evaporation compared to filtered ones. The tensile data of $\mathrm{CNC}_{\mathrm{H}_{2} \mathrm{SO}_{4}}$ are 

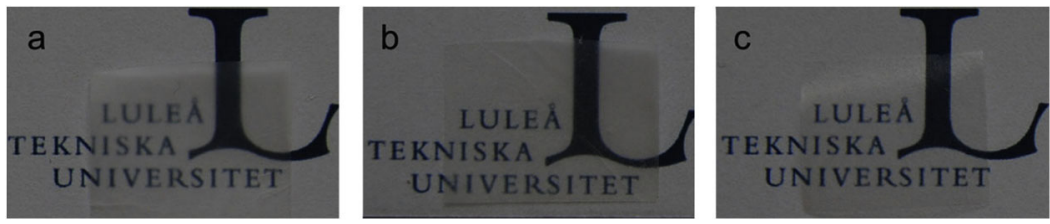

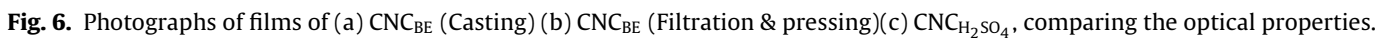

not presented here, due to the high brittleness of the films which resulted in unreliable values with high standard deviation.

\subsection{Optical properties}

The optical properties of the $\mathrm{CNC}_{\mathrm{BE}}$ films (Fig. 6a) and mats (Fig. 6b) are shown in Fig. 6 and were compared with $\mathrm{CNC}_{\mathrm{H}_{2} \mathrm{SO}_{4}}$ (Fig. 6c). All the films showed transparency, but the highest transparency was observed for $\mathrm{CNC}_{\mathrm{H}_{2} \mathrm{SO}_{4}} \mathrm{UV}$ - visual data at $540 \mathrm{~nm}$,

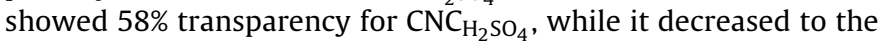
range of 16 and $12 \%$, respectively, for $\mathrm{CNC}_{\mathrm{BE}}$ casted and $\mathrm{CNC}$ filtered and pressed (curves not shown). The reason for lower transparency for $\mathrm{CNC}$ from bioethanol process was attributed to nanocrystals with lengths higher than wavelength of light (Herrera et al., 2012 b). It was also noted that casting resulted in films with better transparency than filtration and pressing, even though the differences were minimal. The higher transparency for casted films may be due to less voids and compacted films and is in agreement with the mechanical data discussed in Section 3.3. However, in general, the transparency values obtained are lower than those found in some earlier reports for nanocellulose (Herrera et al., 2012b; Uetani and Yano, 2011).

\subsection{Cytocompatibility}

Fig. 7 shows the cell adhesion and growth of primary human cells and $\mathrm{L} 929$ on negative control and $\mathrm{CNC}_{\mathrm{BE}}$. The films surfaces of $\mathrm{CNC}_{\mathrm{BE}}$ showed the growth of cells after 15 days of incubation indicating its non-toxic and cytocompatible nature. The study shows
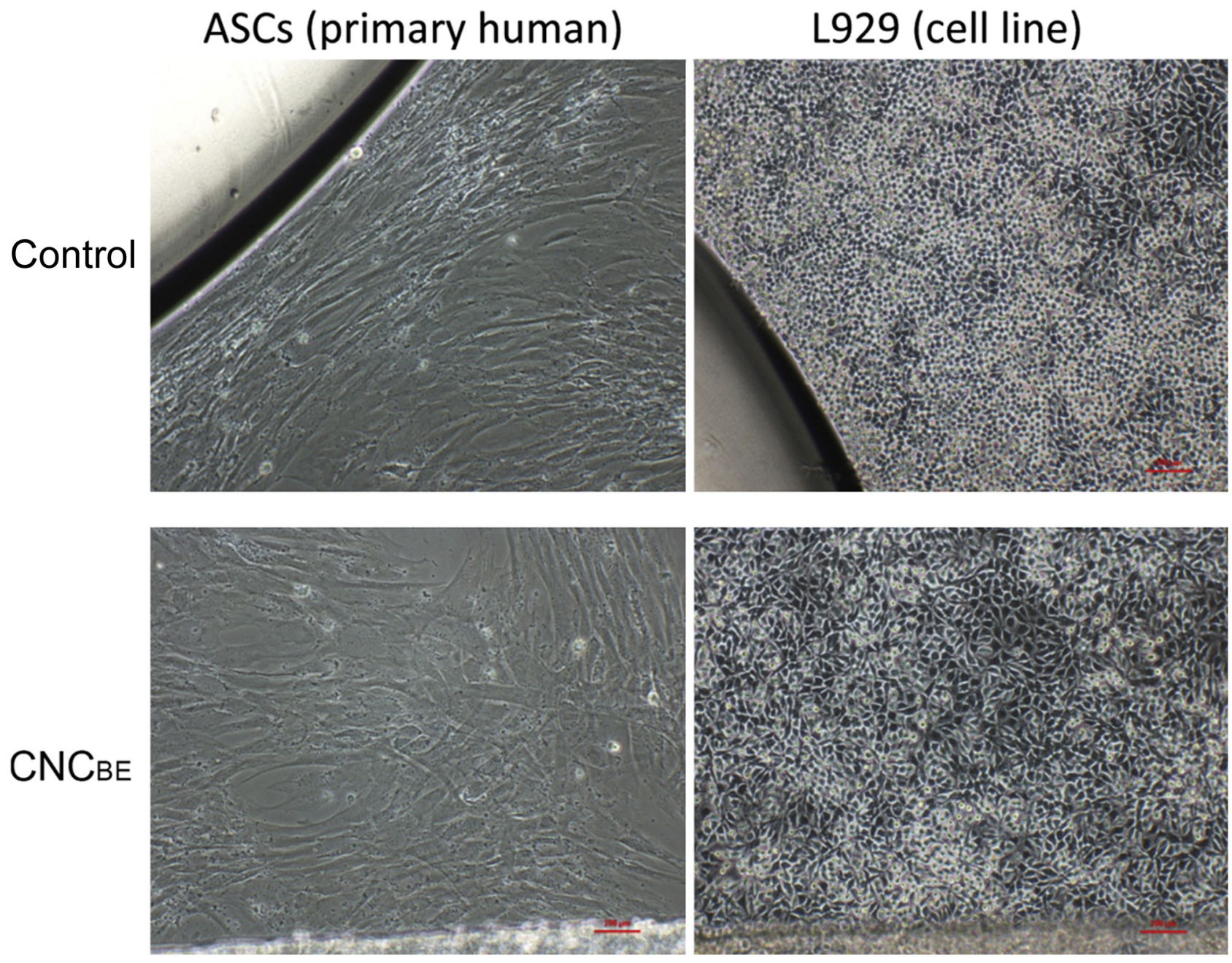

Fig. 7. Images showing adhesion and growth of primary human cells and L929 cells on the negative control and films of $\mathrm{CNC}_{\mathrm{BE}}$ after 15 days of incubation. 
the potential of $\mathrm{CNC}_{\mathrm{BE}}$ in biomedical products and implants where cell viability is crucial.

\subsection{Process efficiency}

The adopted processing route resulted in scaled-up production of $\mathrm{CNC}$ in the lab. The processing route achieved $\mathrm{CNC}_{\mathrm{BE}}$ yield in the range of $600 \mathrm{~g} /$ day (excluding the pilot-scale acid hydrolysis process and the cellulose refining step), which is a major improvement compared to $50 \mathrm{~g} /$ week in lab-scale processing.

The energy consumption for the mechanical isolation step at laboratory scale was estimated to be $30 \mathrm{kWh} / \mathrm{kg}$ for $\mathrm{CNC}_{\mathrm{BE}}$. The total energy consumption for the scaled-up process including industrial/pilot-scale steps is not discussed here and will be reported in detail separately.

\section{Conclusions}

The isolation of cellulose nanocrystals from wood chips via bioethanol pilot-scale unit resulted in $\mathrm{CNC}_{\mathrm{BE}}$ processing in the range of $600 \mathrm{~g} /$ day.

$\mathrm{CNC}_{\mathrm{BE}}$ produced by the scaled-up processes had cellulose I structure and negative zeta potential being related to the surface groups providing interactions with positively charged entities. The $\mathrm{CNC}_{\mathrm{BE}}$ films had mechanical strength as high as $204 \mathrm{MPa}$ and modulus of $16 \mathrm{GPa}$, showing their potential as nanoreinforcement. The nanocrystals were also found to be cytocompatible towards primary human cells and L929 cells indicating potential in biomedical applications.

The new process route developed can be adopted easily by research laboratories and small-scale industries to produce nanocrystals in larger scale at the point of use, via mechanical isolation of cellulose from bioethanol production.

\section{Acknowledgments}

Financial support from the European Commission under EU FP7, NMP4-SL-2012-280519, NanoSelect is gratefully acknowledged. The authors wish to thank Dr. Anuttam Patra, Department of Civil, Environmental and Natural Resources Engineering, LTU, Sweden for help with UV/Visual measurements. Mirjam Fröhlich and Lenart Girando, EDUCELL , Slovenia is acknowledged for biocompatabilty data. Processum Biorefineries, More Research and SEKAB E-technologies Örnsköldsvik Sweden are gratefully acknowledged for providing raw materials and cellulose purification.

\section{References}

Bondeson, D., Mathew, A.P., Oksman, K., 2006. Optimization of the isolation of nanocrystals from microcrystalline cellulose by acid hydrolysis. Cellulose 13 , $171-180$
Chauve, G., Bras. J., 2014. Industrial point of view of nanocellulose materials and their possible applications, Ch 14, In Handbook of Green Materials, Processing Technologies, Properties and Applications. Vol 1. K Oksman, A, Mathew, M, Sain, A Bismarck and O Rojas, (Eds). World Scientific ISBN: 978-981-4566-45-2 pp. 234-252.

Dufresne, A., 2008. Cellulose-based composites and nanocomposites, In Monomers, Polymers and Composites from Renewable Resources, Elsevier, pp. 401-418.

Edgar, C.D., Gray, D.G., 2003. Smooth model cellulose I surfaces from nanocrystals suspensions. Cellulose 10, 299-306.

Eichhorn, S., Dufresne, A., Aranguren, M., Marcovich, N., Capadona, J., Rowan, S. Weder, C., Thielemans, W., Roman, M., Renneckar, S., Gindl, W., Veigel, S., Keckes, J., Yano, H., Abe, K., Nogi, M., Nakagaito, A., Mangalam, A., Simonsen, J., Benight, A., Bismarck, A., Berglund, L., Peijs, T., 2010. Review: Current international research into cellulose nanofibres and nanocomposites. J. Mater. Sci. 45, 1-33.

FutureMarkets, Inc, Market Study-Nanocellulose: a technology and market study-Version 2 (2012). http://www.futuremarketsinc.com/index.php? option $=$ com_content $\&$ view $=$ article $\&$ id $=206 \&$ Itemid $=82$

Han, J.S., Rowell, J.S., 1996. Chemical composition of fibers. In: Rowell, R.M., Young, R.A., Rowell, J. (Eds.), Paper and Composites from Agrobased Resources. CRC Press, London.

Herrera, M.A. Mathew, A.P., Oksman, K., 2012a. Comparison of cellulose nanowhiskers extracted from industrial bio-residue and commercial microcrystalline cellulose. Mater. Lett. 71, 28-31.

Herrera, M.A., Mathew, A.P., Oksman, K., 2012. Characterization of cellulose nanowhiskers: A comparison of two industrial bio-residues, Mater. Sci. Eng. 31, 012006.

Hon, D.N.S., ed, 1996. Chemical Modification of Lignocellulosic Material, Marcel Dekker Inc., New York, pp. 11-17.

Jonoobi, M., Mathew, A.P., Oksman, K., 2012. Producing low-cost cellulose nanofiber from sludge as new source of raw materials. Ind. Crops Pro0, 232-238.

Karim, Z., Mathew, A.P., Oksman, K., Grahn, M., Mouzon, J., 2014. Nanoporous membranes containing cellulose nanocrystals as functional additive: Evaluation of removal of dyes from water. Carbohydrate Polymers. (submitted).

Krässing, H.A., 1996. Cellulose: Structure, Accessibility and Reactivity. Volume11. (Netherlands, Gordon and Breanch Science Publisher). Chapter 4.

Klemm, D., Heublein, B., Fink, H.P., Bohn, A., 2005. Cellulose: fascinating biopolymer and sustainable raw material. Angew. Chem. Int. Ed. Engl. 44 (22), $3358-3393$.

Liu, P., Sehaqui, H., Tingaut, P., Wichser, A., Oksman, K., Mathew, A.P., 2014. Biobased nanomaterials for capturing silver ions $(\mathrm{Ag}+)$ from water via surface adsorption. Cellulose 21, 449-461.

Oksman, K., Etang, J.A., Mathew, A.P., Jonoobi, M., 2011. Cellulose nanowhiskers separated from a bio-residue from wood bioethanol production. Biomass Bioenergy $35,146-152$.

Marchessault, R.H., 1959. Liquid crystal systems from fibrillar polysaccharides Nature 184, 632-633.

Mathew, A.P., Laborie, M.G., Oksman, K., 2009. Cross-Linked chitosan/chitin crystal nanocomposites with improved permeation selectivity and $\mathrm{pH}$ stability. Biomacromolecules 10, 1627-1632.

Roman, M., Winter, W., 2004. Effect of sulfate groups from sulfuric acid hydrolysis on the thermal degradation behavior of bacterial cellulose. Biomacromolecules $5,1671-1677$

Rånby, B.G., 1952. The cellulose micelles. TAPPI 35 (2), 53-58.

Samir, M.A.S.A., Alloin F., Dufresne A., 2005. Review of recent research into cellulosic whiskers, their properties and their application in nanocomposite field. Biomacromolecules 6, 612-626.

Segal, L., Greely, J.J, Martin, A.E., Conrad, C.M., 1959. An empirical method for estimating the degree of crystallinity of native cellulose using $x$-ray diffractometer Text. Res. J 29:786-794.

Siro, I., Plackett, D., 2010. Microfibrillated cellulose and new nanocomposite materials. A review. Cellulose 17, 459-494.

Siqueira, G., Bras, J., Dufresne, A., 2010. New process of chemical grafting of cellulose nanoparticles with a long chain isocyanate. Langmuir 26, 402-411.

Uetani, K., Yano, H., 2011. Nanofibrillation of wood pulp using a high-speed blender. Biomacromolecules 12 (2), 348-353. 